\title{
Padrões espaciais de desmatamento e a estimativa da exatidão dos mapas do PRODES para Amazônia Legal Brasileira
}

\author{
Spatial deforestation patterns and the accuracy of deforestation mapping for the \\ Brazilian Legal Amazon
}

\author{
Luis Eduardo Pinheiro Maurano ${ }^{\mathrm{I}}$, Maria Isabel Sobral Escada ${ }^{\mathrm{II}}$, \\ Camilo Daleles Renno ${ }^{\text {III }}$
}

\begin{abstract}
Resumo
O Instituto Nacional de Pesquisas Espaciais(INPE) opera desde 1988o Projetode Monitoramentodo Desmatamento na Amazônia por Satélites (PRODES), cujo principal objetivo é fornecer taxa anual de desmatamento florestal da Amazônia Legal Brasileira utilizando imagens de satélite de sensoriamento remoto. Esse levantamento envolve o mapeamento de mais de quatro milhões de $\mathrm{km}^{2} \mathrm{e}$ os resultados obtidos são utilizados pelo governo brasileiro no estabelecimento e acompanhamento das políticas públicas relativas ao controle e combate ao desmatamento. Este dado tem sido produzido e divulgado em base anual desde 1988, porém, uma avaliação sobre a qualidade dos dados nunca foi estabelecida. Assim, o objetivo deste trabalho foi desenvolver uma metodologia para estimar índices de exatidão do mapeamento das áreas desmatadas apontadas pelo PRODES para o ano de 2014, a partir de uma amostragem estratificada de padrões de desmatamento mapeados em células de 50 x $50 \mathrm{~km}$. O mapeamento desses padrões foi realizado a partir do estabelecimento e uso de uma tipologia de padrões de desmatamento, métricas de paisagem e técnica de mineração de dados. Pontos amostrais representativos de cada padrão de desmatamento foram sorteados aleatoriamente e avaliados visualmente por especialistas independentes. Como resultado dessa avaliação foi possível estabelecer o nível exatidão global do mapeamento em questão, estimado em 93\% e com índices de omissão e de inclusão estimados em 7\% e 1,5\%, respectivamente. Padrôes como espinha de peixe, multidirecional e consolidado, considerados mais complexos, apresentaram menores índices de acerto, mostrando coerência e indicando que maior atenção deve ser dada ao seu mapeamento. Os resultados apresentados, de uma forma geral, se mostraram consistentes, indicando que a metodologia desenvolvida pode ser replicada em mapeamentos similares.
\end{abstract}

Palavras-chave: Mapeamento de desmatamento; Uso da terra; Sensoriamento remoto; Web-GIS e avaliação de mapeamento

\begin{abstract}
Since 1988, the Brazilian National Institute for Space Research (Instituto Nacional de Pesquisas Espaciais - INPE) has been executing the annual inventory of forest cover loss in the Legal Amazon using satellite data under the Program for Deforestation Monitoring in the Brazilian Legal Amazon (PRODES). This survey comprises mapping more than four million squared kilometers and the produced information are employed by the Brazilian government to evaluate and establish public policies related to the control and counter deforestation. This data has been produced and published annually since 1988. However, its accuracy is not known. Therefore, this work objective is to develop a methodology to estimate the accuracy of the deforested areas mapped by PRODES for the year 2014 using stratified sampling of the deforestation patterns mapped in 50 by $50 \mathrm{Km}$ cells. Mapping these patterns was accomplished by establishing and using a typology of deforestation patterns, landscape metrics and data mining techniques. Typical sample points of each deforestation pattern of were randomly drawn and analyzed visually by independent experts. This evaluation results established that the global accuracy level of the mapping under study is estimated to be $93 \%$, with omission and commission indices estimates being $7 \%$ and $1.5 \%$, respectively. Patterns such as fishbone, multidirectional and consolidated ones, which are considered the most complexes, present the lowest indexes of correctness, showing coherence and indicating that they should be mapped with more rigor. The presented results are consistent in a general way, indicating that the developed methodology can be applied to similar mappings.
\end{abstract}

Keywords: Deforestation mapping; Land use; Remote sensing; Web-GIS and mapping assessment

Ciência da Computação, MSc., Tecnologista Sênior do Instituto Nacional de Pesquisas Espaciais, Av. dos Astronautas, 1758, CEP 12227-010, São José dos Campos (SP), Brasil. luis.maurano@inpe.br (ORCID: 0000-0003-1842-244X)

II Ecóloga, Dra., Tecnologista Sênior do Instituto Nacional de Pesquisas Espaciais, Av. dos Astronautas, 1758, CEP 12227-010, São José dos Campos (SP), Brasil. isabel.escada@inpe.br (ORCID: 0000-0002-5822-8265)

III Engenheiro Agrônomo, Dr., Tecnologista Sênior do Instituto Nacional de Pesquisas Espaciais, Av. dos Astronautas, 1758, CEP 12227-010, São José dos Campos (SP), Brasil. camilo.renno@inpe.br (ORCID: 0000-0001-9920-4473) 


\section{Introdução}

Amazônia Legal Brasileira compreende $60 \%$ da floresta amazônica - a maior floresta tropical contínua do planeta fornecendo importantes serviços ecossistêmicos como a provisão de água, alimentos, madeira, fibras, além de atuar como uma eficiente bomba, reciclando a água sobre toda a extensão da floresta, exercendo um papel preponderante no ciclo hidrológico que contribui para regular o clima da região (SPRACKLEN et al., 2012).

Apesar da grande importância da floresta Amazônica na regulação do clima, na manutenção da biodiversidade e na provisão de serviços ambientais, o processo de ocupação da Amazônia das últimas décadas não primou pela sua conservação. Esse processo, do ponto de vista da perda da cobertura florestal, foi pouco relevante até a década de 50-60, quando foi iniciada a construção dos primeiros eixos rodoviários para conectar essa região com o restante do país, como as rodovias Belém-Brasília e Brasília-Acre. Após os anos 70, a ocupação da Amazônia passou a ser uma atividade prioritária para o Brasil e o governo federal começa a apoiá-la, subsidiando a ocupação de terras em projetos de expansão agropecuária. As políticas de ocupação combinaram os empreendimentos de exploração econômica com estratégias geopolíticas, como a construção de uma rede de estradas, de hidroelétricas e de telecomunicações, juntamente com o incentivo às atividades de agropecuária, mineração e madeireira (BECKER, 2005; VALERIANO et al., 2012). A Amazônia deixou de ser apenas uma fronteira de expansão agropecuária e se constituiu como um território que apresenta estruturas produtivas próprias e projetos variados que envolvem a presença e ações diferentes atores (BECKER, 2005). Hoje a produção agropecuária da região tem uma contribuição importante para o agronegócio brasileiro e, consequentemente, no Produto Interno Bruto (PIB) regional e nacional. De acordo com dados do projeto de mapeamento do Uso e Cobertura da Terra na Amazônia Legal (TerraClass) (ALMEIDA et al., 2016) desenvolvido pelo Instituto Nacional de Pesquisas Espaciais (INPE) em parceria com a Empresa Brasileira de Pesquisa Agropecuária (EMBRAPA), em 2014, dos $764.000 \mathrm{~km}^{2}$ já apontados pelo Projeto de Monitoramento do Desmatamento na Amazônia Legal por Satélite (PRODES) (INPE, 2016) como desmatados na Amazônia Legal, 63\% eram ocupados por pastagens e 6\% por agricultura, o que mostra a vocação atual da região para a produção agropecuária de larga escala. Por outro lado, a Amazônia sendo submetida a iniciativas que não consideram a temática ambiental e social na mesma proporção. A atual estrutura espacial de ocupação da Amazônia se relaciona com seu processo histórico de ocupação, traduzido pela forte desigualdade na utilização dos seus recursos naturais para produção agropecuária, com a exclusão das populações locais nos processos econômicos produtivos e sem um comprometimento com a sustentabilidade ambiental da região (VIEIRA et al., 2014).

Durante o processo de ocupação, o desmatamento foi o principal vetor das alterações da paisagem na Amazônia. Devido às altas taxas de desmatamento e à preocupação em escala global com o impacto da remoção da cobertura florestal na emissão de gases de efeito estufa, inicia-se a confecção uma série de políticas governamentais voltadas ao controle, fiscalização e combate do desmatamento.

Em 1978 e 1979, o INPE divulga os primeiros trabalhos científicos demonstrando a viabilidade do uso da tecnologia do sensoriamento remoto orbital no mapeamento e quantificação do desmatamento na região (TARDIN et al., 1979 e TARDIN et al., 1978). Porém, somente 10 anos depois, em 1988, tem início de forma sistemática o mapeamento anual do desmatamento por corte raso, através do PRODES. No período de 1988 a 2000, todo processo de mapeamento era feito por processo de interpretação visual sobre imagens do satélite Landsat 5 plotadas em papel fotográfico na escala 1:250.000. De 2000 a 2005 passou-se a utilizar métodos de segmentação e classificação de imagens digitais em um processo semiautomático. Desde então, o mapeamento do desmatamento é realizado por meio de fotointerpretação das imagens diretamente na tela do computador com uso do sistema de informações geográficas TerraAmazon (TERRAAMAZON, 2017) desenvolvido pelo INPE. Desde 2002, todas as informações produzidas no PRODES, como

Ci. Fl., Santa Maria, v. 29, n. 4, p. 1763-1775, out./dez. 2019 
mapas, tabelas e imagens são divulgadas na internet. O PRODES processa anualmente por volta de 215 imagens do sensor Operational Terra Imager (OLI) a bordo do satélite Landsat 8 ou satélites similares, mapeando áreas de corte raso, entendidas como áreas em que ocorreram a remoção total da cobertura florestal primária. A unidade mínima do mapeamento equivale a 6,25 hectares e o produto é compatível com escala cartográfica de 1:250.000.

A taxa de desmatamento gerada pelo PRODES constitui informação importante do governo federal e/ou governos estaduais para a formulação de políticas governamentais voltadas à gestão do uso da terra na Amazônia, bem como, um instrumento de avaliação da eficácia nas suas implementações. Dados do PRODES também têm sido utilizados com sucesso nos acordos voluntários de monitoramento das cadeias produtivas do agronegócio que visam ao combate ao desmatamento na região, tais como a Moratória da Soja (RUDORFF et al., 2011) e o Termo de Ajustamento de Conduta da Pecuária (TAC da Carne) (NEPSTAD et al., 2014). Além de sua importância para políticas públicas nacionais, esse dado tem sido utilizado como referência nas negociações internacionais de mudanças climáticas como a Convenção Quadro das Nações Unidas sobre a Mudança Climática (UNFCCC) e nos modelos de emissão de carbono, reportados nos Relatórios de Inventário Nacional de Emissões de Gases de Efeito Estufa da UNFCCC.

Apesar da série histórica gerada pelo projeto PRODES ter iniciado há cerca de 30 anos, até hoje não se realizaram estudos de larga escala para aferir a qualidade do mapeamento. A literatura recomenda que erros e/ou a exatidão em mapeamentos temáticos devem ser avaliados e relatados, caso contrário, os mapas gerados podem ter pouca utilidade para inferência científica (MCROBERTS, 2011). Card (1982) adverte que usuários não deveriam usar ou considerar um mapa sem alguma estimativa de erro associada a ele e Jensen (2009) aponta algumas fontes de erros inerentes ao processo de mapeamento com dados de sensoriamento remoto e destaca quatro ações para sua redução, como: a) registro dos passos operacionais utilizados; b) documentação dos erros geométricos e temáticos, c) melhoria na legenda e d) uso de métodos de avaliação de exatidão. A incorporação de medidas de rastreio de erros possibilita gerar informações mais confiáveis e que conferem maior credibilidade ao mapeamento proposto. Pontus et al. (2014) indicam que usuários e produtores de mapeamento de uso e cobertura da terra por sensoriamento remoto estão interessados em comunicar e entender a qualidade dos mapas, tornando uma necessidade a avaliação da exatidão desses mapas de maneira consistente e transparente.

$\mathrm{Na}$ Amazônia observa-se que desiguais processos de ocupação do território e usos da terra produzem diferentes padrões espaciais de desmatamento (GEIST e LAMBIN, 2001; SAITO, 2011), como o padrão espinha de peixe que representa a ocupação de pequenos produtores rurais em projetos de assentamento do Instituto Nacional de Colonização e Reforma Agrária (INCRA) ou o padrão geométrico que representa grandes fazendas de produção agropecuária de larga escala. Esses padrões apresentam arranjos espaciais diferenciados que podem ser mais ou menos complexos e heterogêneos, influenciando no mapeamento do desmatamento e, consequentemente, em sua exatidão. Partindo dessa premissa o presente artigo tem como objetivo calcular os índices de exatidão do mapeamento das áreas desmatadas do PRODES na região da Amazônia Legal para o ano de 2014, sendo utilizada a tipologia de padrões de desmatamento proposta por Saito et al. (2011) de forma a estimar e associar possíveis erros encontrados no mapeamento aos diferentes padrões.

\section{Material e método}

Para a estimativa índices de exatidão considerando os diferentes padrões espaciais de desmatamento, os procedimentos metodológicos foram realizados em duas etapas: 1) Regionalização da área de estudo baseada nos padrões de desmatamento representados em células de 50 x $50 \mathrm{~km}$, a partir da tipologia de padrões de desmatamento e do uso de técnicas de mineração de dados e 2) Estabelecimento de um esquema amostral para avaliação da confiabilidade do desmatamento na Amazônia Legal, considerando o mapa e padrões de desmatamento. 


\section{Área de estudo}

A área de estudo escolhida para este trabalho foi a Amazônia Legal brasileira (Figura 1). Instituída originalmente pela Lei 1.806, Amazônia Legal brasileira é um conceito políticoadministrativo que visou estabelecer o limite de atuação da então Superintendência do Plano de Valorização Econômica da Amazônia (SPVEA), órgão federal substituído em 1966 pela Superintendência para o Desenvolvimento da Amazônia (SUDAM). A região é constituída pelos estados do Mato Grosso, Pará, Acre, Amazonas, Roraima, Rondônia, Amapá, Tocantins e Maranhão (neste caso só a parte a oeste do meridiano $44^{\circ}$ ), totalizando aproximadamente 5,2 milhões de $\mathrm{km}^{2}$ o que corresponde a cerca de $60 \%$ do território brasileiro. Apesar de sua grande extensão territorial, a demografia da região indica pouco mais de 24 milhões de habitantes, ou seja, $12,4 \%$ da população nacional e a menor densidade demográfica do país com cerca de quatro habitantes por $\mathrm{km}^{2}$ (IBGE, 2017).

Esta região de estudo compreende a área de mapeamento estabelecida pelo PRODES que envolve apenas as regiões que apresentam fisionomia florestal. Outros tipos de vegetação como vegetação de cerrado, campos e vegetação de várzea não são mapeadas. Nesse trabalho, apenas as áreas desmatadas por corte raso são consideradas, áreas que apresentam degradação florestal, seja por extração seletiva de madeira e/ou por queimada, não são contempladas no mapeamento.

\section{Figura 1 - Área de estudo deste trabalho - Amazônia Legal brasileira, representada por um mosaico de imagens Landsat 5 do ano 2000 na composição 5R4G3B.}

Figure 1 - Study area - Brazilian Amazon, represented by a Landsat 5 mosaic (5R4G3B).

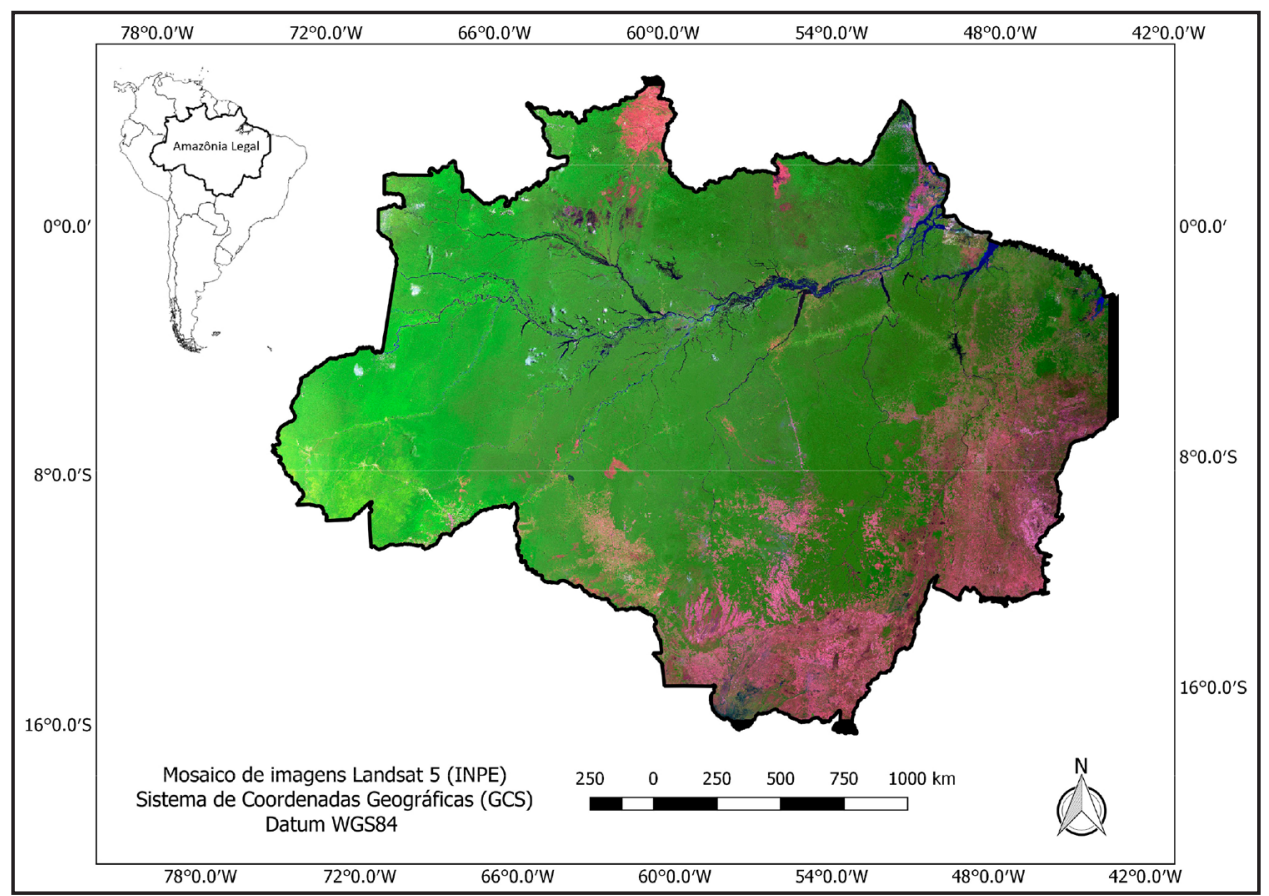

Fonte: Autores (2018)

\section{Métricas de paisagem para mapeamento de padrões de desmatamento}

As métricas de paisagem correspondem a índices utilizados para quantificar sua estrutura, descrevendo atributos dos elementos que a compõe como, área, tamanho, forma, abundância, 
densidade, Essas métricas são normalmente utilizadas na avaliação/caracterização da mudanças no padrão da paisagem o que as torna importantes no monitoramento florestal e nos estudos que buscam relacionar padrões de desmatamento aos diferentes processos de mudança da cobertura da terra. Para confeccionar as análises de padrões de desmatamento foram empregados dados do PRODES consolidados à base de desmatamento acumulado até o ano de 2014 em uma única classe. Fatores como área, perímetro e forma dos polígonos de desmatamento, a proximidade dos desmatamentos em relação às áreas de borda de floresta e área de desmatamento acumulado, entre outros foram extraídos. Esses elementos podem ter influência direta na interpretação das imagens e no correto mapeamento dos polígonos desmatados, por essa razão foi utilizada uma tipologia de padrões de desmatamento desenvolvida por Saito et al. (2011), baseada em células na resolução de $50 \times 50 \mathrm{~km}$, com sete principais categorias de padrões encontradas nos dados do PRODES, conforme descrito na Tabela 1. Para toda Amazônia Legal, este espaço celular é representado por um total de 2.164 células.

De acordo com a Tabela 1 pode-se observar que padrões de desmatamento como o difuso, linear, geométrico, são padrões mais simplificados, que apresentam homogeneidade além de formas e tamanhos bem definidos, enquanto os padrões espinha de peixe, consolidado e multidirecional, apresentam maior heterogeneidade e complexidade dos polígonos de desmatamento e de seu arranjo espacial.

Tabela 1 - Padrões de desmatamento utilizados. Adaptado de Saito et al., (2011).

Table 1 - Deforestation patterns. Adapted from Saito et al., (2011).

\begin{tabular}{|c|c|c|c|}
\hline Tipologia/Descrição & & Tipologia/Descrição & \\
\hline $\begin{array}{l}\text { Difuso: Manchas } \\
\text { pequenas, isoladas; } \\
\text { Forma variada, } \\
\text { irregular; Baixa a } \\
\text { média densidade; } \\
\text { Distribuição uniforme. }\end{array}$ & $2 \therefore$. & $\begin{array}{l}\text { Espinha de Peixe: } \\
\text { Manchas grandes } \\
\text { alongadas e lineares com } \\
\text { ramificações semelhantes } \\
\text { à vértebra de peixe; média } \\
\text { densidade. }\end{array}$ & 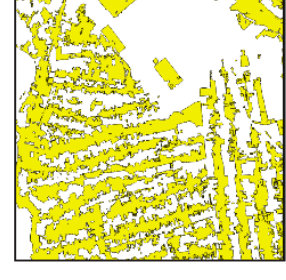 \\
\hline $\begin{array}{l}\text { Linear: Manchas } \\
\text { médias e grandes; } \\
\text { Manchas de forma } \\
\text { alongada dispostas } \\
\text { ao longo das vias } \\
\text { de acesso; Baixa } \\
\text { densidade. }\end{array}$ & $\frac{1}{2}$ & $\begin{array}{l}\text { Consolidado: Manchas } \\
\text { grandes e contínuas de } \\
\text { desmatamento; Forma } \\
\text { variada; Densidade baixa } \\
\text { e áreas pequenas de } \\
\text { remanescentes florestais; } \\
\text { Manchas compactas. }\end{array}$ & 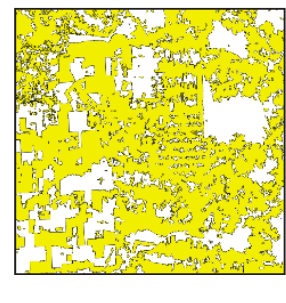 \\
\hline $\begin{array}{l}\text { Multidirecional: } \\
\text { Manchas pequenas } \\
\text { isoladas dispostas ao } \\
\text { longo dos rios; Baixa } \\
\text { densidade. }\end{array}$ & 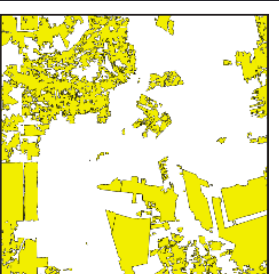 & $\begin{array}{l}\text { Floresta: Células com } \\
\text { manchas grandes e } \\
\text { contínuas de vegetação do } \\
\text { tipo floresta primária. }\end{array}$ & \\
\hline $\begin{array}{l}\text { Geométrico Regular: } \\
\text { Manchas médias a } \\
\text { grandes e isoladas; } \\
\text { Forma geométrica } \\
\text { regular; Baixa a média } \\
\text { densidade. }\end{array}$ & 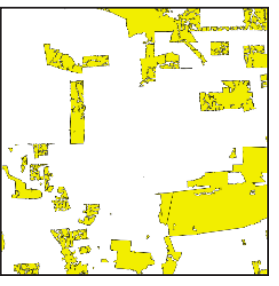 & & \\
\hline
\end{tabular}




\section{Mineração de Dados}

Esta fase do trabalho foi realizada no aplicativo Geographical Data Mining Analyst (GeoDMA) (KORTING et al., 2013) que é um sistema que contém ferramentas de análise de métricas de paisagens, manipulação e análise de dados multitemporais. O GeoDMA é um plugin do sistema TerraView (INPE, 2017). A etapa constituiu de quatro fases distintas: 1) extração de métricas da paisagem baseada no mapa de desmatamento acumulado do PRODES até 2014 e delimitado pelas células de $50 \times 50 \mathrm{~km}$. Com base neste ambiente de espaço-celular foram calculadas 21 métricas da paisagem baseadas nas formulações propostas por McGarigal et al. (1995), no GeoDMA; 2) seleção de amostras de treinamento; 3) classificação das células, utilizando um algoritmo de árvore de decisão C5.0 em que são selecionadas as métricas que melhor separam os padrões e também os limiares que distinguem as diferentes classes de desmatamento e 4) validação do mapa gerado.

\section{Seleção de amostras de treinamento}

A seleção de amostras de treinamento foi feita manualmente elegendo de maneira visual um conjunto de células representativas de cada padrão de desmatamento, descritos na Tabela 1. O total de células selecionadas foi de 194, sendo: a) Multidirecional, 36 amostras; b) Geométrico Regular, 36 amostras; c) Consolidado, 29 amostras; d) Difuso, 29 amostras; d) Espinha de Peixe, 19 amostras; e) Linear, 28 amostras e; f) Floresta, 13 amostras. Este número de amostras de treinamento representou aproximadamente $9 \%$ do total de células pertencentes à área de estudo e procurou caracterizar de maneira uniforme os vários tipos de padrões de desmatamento encontrados na região.

\section{Classificação}

O processo de classificação supervisionada apoiado no algoritmo de árvore de decisão versão C 5.0 foi realizado por um programa escrito na linguagem R. A versão C 5.0 é uma nova geração de Machine Learning Algorithms (MLAs) baseado em árvores de decisão. Isso significa que as árvores são construídas a partir da lista de possíveis atributos e conjuntos de amostras de treinamento e então elas podem ser utilizadas para classificar conjuntos subsequentes de amostras. No total foram executadas 100 classificações por árvores de decisão totalmente independentes que utilizaram em cada uma delas, $75 \%$ das amostras de treinamento para serem aplicadas na classificação propriamente dita e $25 \%$ das amostras para serem utilizadas como teste da classificação. Para geração do mapa final com os padrões de desmatamento, foram utilizados valores que representaram a moda, ou seja, a classe mais frequente entre as 100 classificações obtidas para cada célula de 50 x $50 \mathrm{~km}$. Uma descrição detalhada da versão C5.0 pode ser encontrada em Quinlan (2017).

\section{Sorteio do painel amostral para validação}

A metodologia utilizada neste trabalho baseia-se na avaliação dos dados gerados pelo PRODES em 2014, e utiliza uma abordagem de validação de pontos amostrais sorteados sobre a base de dados. A solução empregada foi gerar um painel amostral de pontos por meio de sorteio aleatório estratificado utilizando o espaço-celular de resolução de 50 x $50 \mathrm{~km}$ como referência, valendo-se do mapa de padrão de desmatamento obtido com a classificação descrita no tópico acima. Inicialmente foi sorteado aleatoriamente o total de 120 células, sendo 20 células para cada padrão de desmatamento. Para cada célula sorteada, foram gerados pontos amostrais restritos ao seu limite geográfico. Empiricamente, estabeleceu-se o sorteio de 20 pontos por célula, sendo 15 
pontos sobre polígonos de desmatamento do PRODES de 2014 e 5 pontos sobre área de floresta, obtendo-se um total de aproximadamente 2000 pontos amostrais.

\section{Validação dos pontos amostrais}

Para classificação dos pontos amostrais foi utilizada uma ferramenta apoiada no conceito de web gis desenvolvida para esta finalidade e que permite realizar tarefas de validação a "distância". Esta ferramenta combina, em uma página de internet, os pontos amostrais sorteados e armazenados no sistema gerenciador de banco de dados PostGis, os recortes de imagens do satélite Landsat e RapidEye e as imagens de alta resolução disponíveis no ambiente Google Maps, além da série temporal Índice de Vegetação da Diferença Normalizada (NDVI) extraída do sensor Moderate Resolution Imaging Spectroradiometer (MODIS) (QUEIROZ et al., 2015). A validação foi executada por três auditores independentes, em que cada auditor classificou cada um dos 1855 pontos amostrais, sendo utilizado o valor da moda, ou seja, o valor mais frequente entre eles, para atribuição da classe final de referência. A interface principal da ferramenta de validação utilizada no processo de classificação dos pontos amostrais está apresentada na Figura 2. Maiores detalhes desta ferramenta podem ser encontrados em Maurano e Adami (2017) e Adami et al., (2012).

\section{Figura 2 - Interface da ferramenta de validação. A) Seleção dos pontos; B) Ponto para validação; C) Imagens Landsat e RapidEye; D) Formulário para classificação; E) Série temporal NDVI e F) Google Maps.}

Figure 2 - Validation tool interface. A) Point selection; B) Validation point; C) Landsat and RapidEye images; D) Classification form; E) Time series NDVI and F) Google Maps.

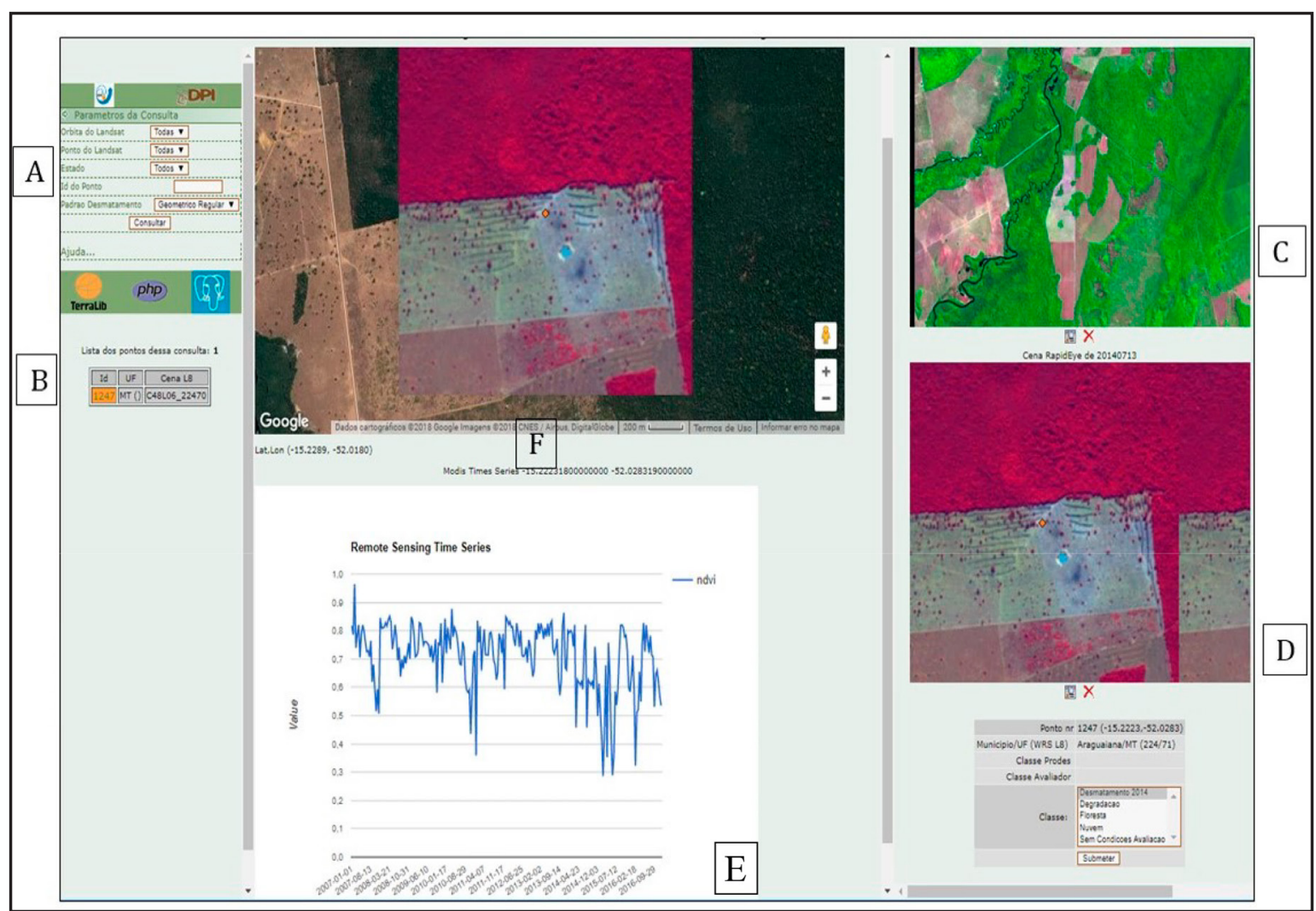

Fonte: Autores (2018) 


\section{Resultados e discussão}

\section{Resultados da classificação}

O mapa final com os padrões de desmatamento obtidos pelo método de classificação por algoritmo de árvore de decisão C5.0 é apresentado na Figura 3.

Figura 3 - Mapa com padrões de desmatamento resultante do processo classificação.

Figure 3 - Pattern deforestation map resulting from the classification process.

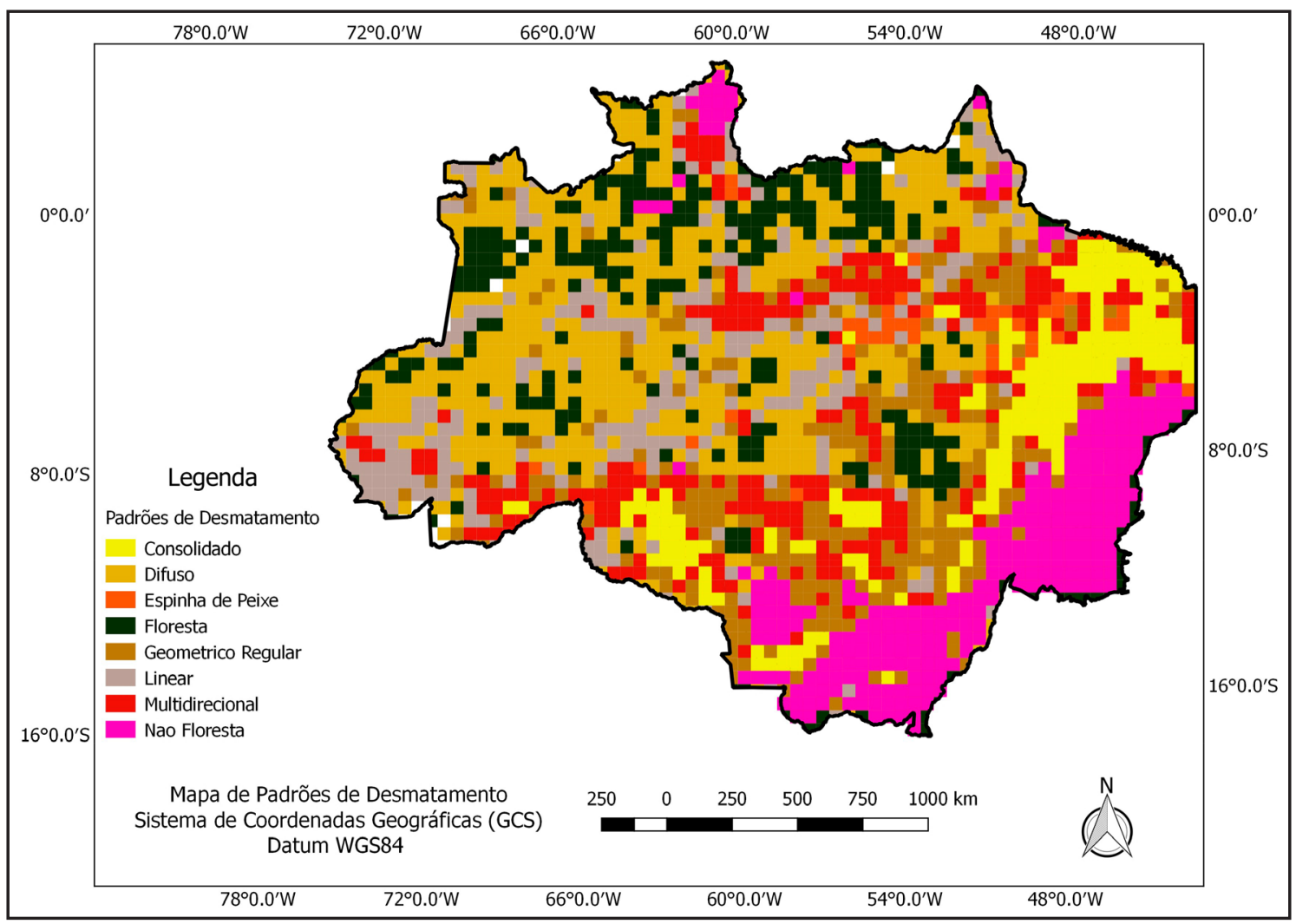

Fonte: Autores (2018)

Destaca-se que no mapeamento executado pelo PRODES a classe denominada Não Floresta (Figura 3) representa qualquer tipo de vegetação que, pela definição do projeto Radam Brasil/IBGE, não seja do tipo: Ombrófila Densa, Floresta Ombrófila Aberta, Floresta Estacional Decidual, Áreas de Formação Pioneira de Influência Fluvial (Vegetação Aluvial),Vegetação Lenhosa Oligotrófica dos Pântanos e das Acumulações Arenosas (Campinarana) e áreas de Tensão Ecológica (Contato floresta/cerrado), com predominância de Fisionomia Florestal.

Visando obter um índice que aferisse a qualidade do mapa de padrões de desmatamento resultante do processo classificação, foi gerado uma matriz de confusão e respectivos índices de exatidão do produtor e usuário (Tabela 2), comparando os dados da classificação obtida contra um conjunto de 113 células selecionadas de forma que todos os padrões de desmatamento envolvidos tivessem representação. Estas 113 células foram classificadas visual e manualmente e este conjunto foi considerado como dado de referência. O índice Kappa obtido ficou em 0,88 e a exatidão global em $90,2 \%$. Os valores verificados permitem atestar o bom resultado do mapa final produzido. As confusões verificadas entre o padrão Multidirecional, principalmente com 
o padrão Geométrico Regular, são aceitáveis, pois, em alguns casos, uma mesma célula pode apresentar uma grande heterogeneidade de polígonos que dificulta a identificação do padrão de desmatamento ocasionado confusão durante a classificação.

Tabela 2 - Matriz de confusão da classificação dos padrões de desmatamento.

Table 2 - Confusion matrix of the deforestation pattern classification.

\begin{tabular}{|c|c|c|c|c|c|c|c|c|c|c|}
\hline \multicolumn{11}{|c|}{ Referência } \\
\hline \multirow{10}{*}{ 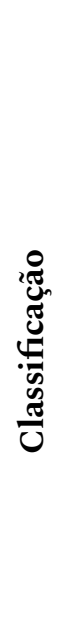 } & & Cons & Dif & EspP & Flo & GeomR & Lin & Mult & $\mathrm{N}$ & EU \\
\hline & Cons & 13 & & & & & & & 13 & $100 \%$ \\
\hline & Dif & & 20 & & & & & & 20 & $100 \%$ \\
\hline & EspP & & & 9 & & & & & 9 & $100 \%$ \\
\hline & Flo & & & & 9 & & & & 9 & $100 \%$ \\
\hline & GeomR & & & & & 21 & 1 & 2 & 24 & $87 \%$ \\
\hline & Lin & & 1 & & & & 11 & 1 & 13 & $84 \%$ \\
\hline & Mult & 1 & & 1 & & 4 & & 19 & 25 & $76 \%$ \\
\hline & $\mathrm{N}$ & 14 & 20 & 10 & 9 & 25 & 12 & 23 & 113 & \\
\hline & EP & $93 \%$ & $100 \%$ & $90 \%$ & $100 \%$ & $84 \%$ & $91 \%$ & $82 \%$ & & \\
\hline
\end{tabular}

Em que: Cons: Consolidado; Dif: Difuso; EspP: Espinha de Peixe; Flo: Floresta; GeomR: Geométrico Regular; Lin: Linear; Mult: Multidirecional; N: número total de amostras, AP: Exatidão Produtor; EU: Exatidão Usuário

\section{Resultados globais}

Concluído o processo de validação dos pontos amostrais realizado pelos três auditores independentes, foi possível estabelecer a matriz de confusão entre os dados do mapeamento do PRODES e os dados validados pelos auditores - aqui tratado como dados de referência, além do cálculo dos índices de exatidão do produtor, do usuário e da exatidão global. A Tabela 3 apresenta estes resultados:

Tabela 3 - Matriz de confusão referente à validação dos dados PRODES 2014.

Table 3 - Confusion matrix related to the validation of the data from PRODES 2014.

\begin{tabular}{|c|c|c|c|c|c|}
\hline \multirow{6}{*}{$\begin{array}{l}\text { n } \\
\text { 됭 } \\
\text { 염 }\end{array}$} & \multicolumn{5}{|c|}{ Referência } \\
\hline & & D2014 & ND2014 & Total & Exatidão Usuário \\
\hline & D2014 & 1349 & 21 & 1370 & $98,5 \%$ \\
\hline & ND2014 & 100 & 385 & 485 & $79,4 \%$ \\
\hline & Total & 1449 & 406 & 1855 & \\
\hline & $\begin{array}{l}\text { Exatidão } \\
\text { Produtor }\end{array}$ & $93,1 \%$ & $94,8 \%$ & & $\begin{array}{c}\text { Exatidão } \\
\text { Global: } 93,5 \%\end{array}$ \\
\hline
\end{tabular}

Em que: *D2014 - Desmatamento; ${ }^{* \star}$ ND2014 - Área não desmatada. 
Os pontos sorteados em área de floresta e/ou em áreas de degradação florestal foram agrupados em uma classe única denominada Área Não Desmatada (ND2014) já que o objetivo do trabalho não era avaliar os erros destas duas classes especificamente, pois o dado do PRODES não as discrimina. Assim, pontos em área de floresta classificados pelos auditores como degradação (e vice-versa) foram considerados como acerto. Os dados da Tabela 3 demonstram o alto nível de acerto do mapeamento do PRODES em 2014. A exatidão global calculada com base na matriz de confusão ficou acima de $93 \%$. Foram detectados baixos índices de omissão 6,9\% (exatidão do produtor $=93,1 \%$ ) e inclusão $1,5 \%$ (exatidão do usuário $=98,5 \%$ ) para a classe de desmatamento D2014. A exatidão do produtor indica a probabilidade de uma classe no mapa de referência ter sido corretamente classificada, enquanto a exatidão do usuário calcula a probabilidade de uma classe no mapa classificado representar a mesma classe de referência (CONGALTON, 1991; PONTUS et al., 2014). Os resultados alcançados neste estudo estão em consonância com estudo semelhante já realizados por Adami et al. (2017).

\section{Resultados por padrão de desmatamento}

Como o objetivo deste trabalho é analisar se o padrão de desmatamento encontrado na Amazônia Legal pode ter influência no processo de detecção dos desmatamentos e assim influenciar nos níveis de erros/acertos do mapeamento, foram calculados os índices de concordância entre a classe original do mapeamento de cada ponto amostral (basicamente as classes Desmatamento 2014 e Área não desmatada) e a classe atribuída pelos auditores. Neste caso, foi utilizado o valor da moda, ou seja, o valor mais frequente entre eles. A Tabela 4 apresenta os resultados desta análise:

Tabela 4 - Distribuição dos erros por padrão de desmatamento.

Table 4 - Error distribution by deforestation pattern.

\begin{tabular}{lccc}
\hline Padrão de desmatamento & Pontos válidos & Qtde. erros & Erro (\%) \\
\hline Difuso & 177 & 4 & 2,3 \\
Linear & 327 & 13 & 4,0 \\
Geométrico Regular & 329 & 23 & 7,0 \\
Multidirecional & 371 & 27 & 7,3 \\
Consolidado & 319 & 24 & 7,5 \\
Espinha de Peixe & 332 & 30 & 9,0 \\
Totais & 1855 & 121 & 6,5 \\
\hline
\end{tabular}

Alguns percentuais de erros relatados merecem ser analisados com mais detalhe, pois apresentam valores que não condizem com as suposições de que padrões de menor complexidade apresentariam menores probabilidades de erro, como é o caso do padrão Geométrico Regular, como pode ser observado na Tabela 3. O padrão Geométrico Regular apresenta uma porcentagem de erro muito próxima aos padrões Multidirecional e Consolidado, que são mais heterogêneos e apresentam polígonos com formas complexas e variadas. Três exemplos foram selecionados para ilustrar os casos em que o erro obtido na validação foi maior do que se esperava. A Figura 4 mostra células classificada como padrão Geométrico Regular, Consolidado e Espinha de Peixe que apresentaram erros bem acima do esperado. 
Figura 4 - (A) Células padrão Geométrico Regular; (B) Consolidado e; (C) Espinha de Peixe.

Figure 4 - Regular Geometric Cell pattern (A), Consolidated (B) and Fishbone (C).

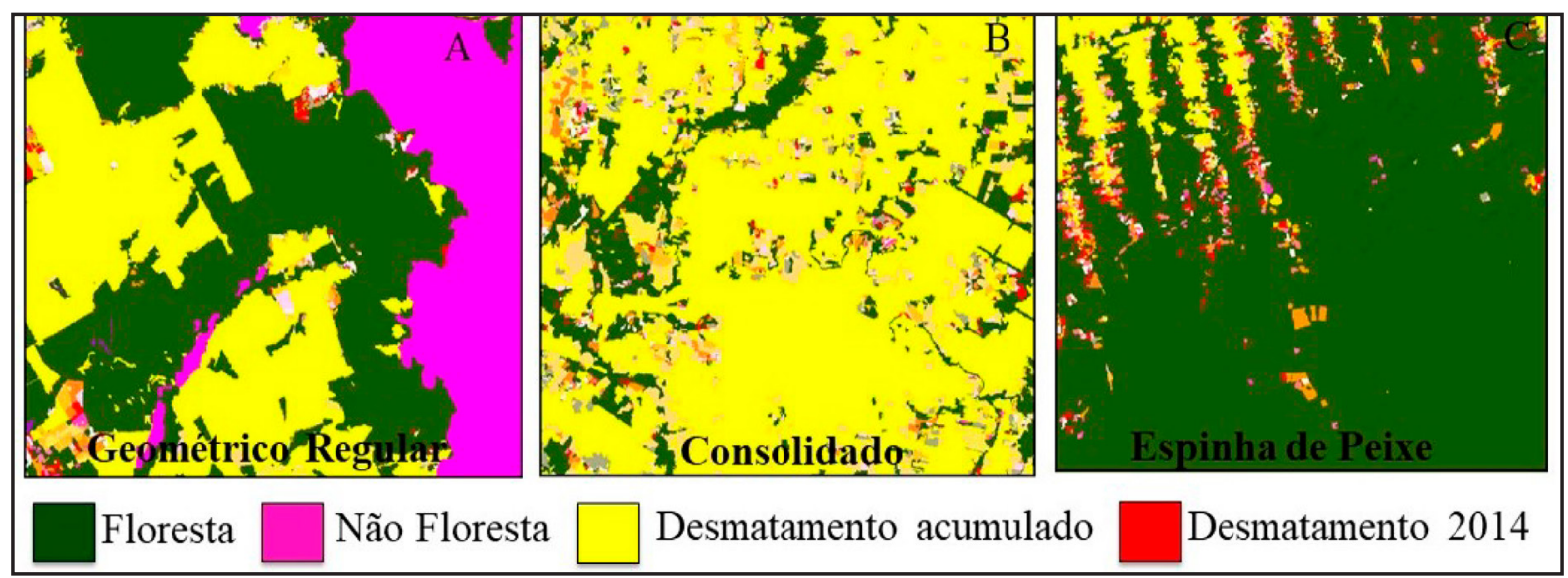

Fonte: Autores (2018)

Analisando o comportamento destas três células tomadas como exemplo em relação ao resultado da validação em cada uma dela, temos:

1) Célula ID C31L08 - padrão Geométrico Regular (Figura 4A): Nesta célula foram validados 15 pontos que apresentaram um erro de 13\%. O padrão Geométrico Regular está bem caracterizado, predominando a forma regular e de tamanho grande. Porém, os polígonos de desmatamento mapeados em 2014 apresentam áreas pequenas, com média de 29 ha/polígono, detectados predominantemente na região de borda das áreas previamente desmatadas. Esses polígonos de desmatamento, por serem pequenos, por apresentarem formas mais complexas e por estarem muito próximos de áreas previamente desmatadas, podem ter apresentado um grau maior dificuldade em seu mapeamento, o que pode ter implicado no aumento dos erros desse padrão. É preciso lembrar que os polígonos de desmatamento de 2014, pequenos e com forma irregular, encontrados na célula em questão, não é o esperado para esse padrão, que apresentam em anos anteriores polígonos com forma geométrica e de grande dimensão.

2) Célula ID C41L17 - padrão Consolidado (Figura 4B): Nesta célula foram validados 16 polígonos que apresentaram um erro de $12,5 \%$. O padrão Consolidado verificado nesta célula mostra uma região com desmatamento acumulado até 2013, bem característico desse padrão, com pouca floresta remanescente. Os 39 polígonos de desmatamento mapeados em 2014 nesta célula apresentam área pequena (média de 14 ha) e encontravam-se localizados em região de borda das áreas previamente desmatadas. Estes fatores podem ter implicado no aumento da quantidade de erros, por representarem mudanças sutis, gerando um grau maior de dificuldade de detecção.

3) Célula ID C42L30 - padrão Espinha de Peixe (Figura 4C): Nesta célula foram validados 16 polígonos que apresentaram um erro de $6,25 \%$. Estimativas mais altas de erro são esperadas para esse padrão, devido ao tamanho reduzido dos polígonos de desmatamento, o que dificulta sua identificação e delimitação. O padrão Espinha de Peixe, verificado nesta célula, mostra uma estrutura típica de desmatamentos feitos em ramais que apresentam áreas pequenas, normalmente associadas ao desmatamento realizado em pequenos estabelecimentos rurais. Os 197 polígonos de desmatamento mapeados em 2014 são de pequenas dimensões (média de 9 ha), realizados em região de borda de áreas previamente desmatadas. Estes fatores, como nos dois exemplos anteriores, podem ter contribuído para o erro detectado na validação. 


\section{Conclusão}

Em mapeamentos como os realizados pelo PRODES, mesmo quando executado por profissionais experientes, seguindo o rigor metodológico na sua elaboração, apresentam erros em seu resultado. Esses erros devem ser avaliados para que estimativas de incertezas possam ser estimadas e associadas a esses dados.

Neste estudo, uma metodologia consistente e reaplicável foi estabelecida de forma a estimar níveis de qualidade do mapeamento produzido pelo PRODES na Amazônia Legal brasileira para o ano de 2014, associados a diferentes padrões de desmatamento que, de acordo com as premissas desse estudo, influenciam a exatidão do mapeamento. $\mathrm{O}$ mapa de padrões de desmatamento espacializado em células de $50 \times 50 \mathrm{~km}$ obtido, possibilitou avaliar a exatidão do mapeamento para cada padrão, a partir dos 1855 pontos amostrais sorteados e avaliados por três auditores independentes. O estudo estimou o nível de exatidão global do mapeamento em 93,5\%, além das exatidões do usuário/produtor que corresponderam a 98,5\% e 93,1\%, respectivamente, para os pontos em área de desmatamento e $79,4 \%$ e $94,8 \%$, respectivamente, para a classe de não desmatamento, indicando uma alta exatidão do mapeamento. A estratificação dos erros por tipos de padrões de desmatamento apresentou resultados condizentes com o que se esperava, indicando que os padrões mais complexos e heterogêneos, com exceção do padrão geométrico regular, foram aqueles que apresentaram menor exatidão e, portanto, devem ser mapeados por intérpretes mais experientes que devem dar maior atenção a essas áreas. O padrão geométrico regular considerado um padrão de menor complexidade e, portanto, um padrão na qual se esperava obter menores porcentuais de erro, apresentou células com polígonos pequenos e irregulares no ano estudado, não representativo desse padrão, o que pode ter influenciado nesse resultado.

Por fim, os resultados obtidos nesse estudo conferem ao mapeamento do PRODES um alto nível de qualidade e confiabilidade e estão em consonância com estudos semelhantes já realizados. O resultado alcançado neste artigo se mostrou satisfatório e encoraja a utilização da metodologia apresentada para aferição da qualidade de dados produzidos em projetos de mapeamento que apresentam características similares.

\section{Referências}

ADAMI, M. et al. A Web Platform Development to Perform Thematic Accuracy Assessment of Sugarcane Mapping in South-Central Brazil. Remote Sensing, USA, v. 4, p. 3201-3214, 2012.

ADAMI, M. et al. A confiabilidade do PRODES: estimativa da acurácia do mapeamento do desmatamento no estado Mato Grosso. In: SIMPÓSIO BRASILEIRO DE SENSORIAMENTO REMOTO, 18, 2017, Santos. Anais... São José dos Campos: INPE, 2017, p. 4189-4196.

ALMEIDA, C. A. et al. High spatial resolution land use and land cover mapping of the Brazilian Legal Amazon in 2008 using Landsat-5/TM and MODIS data. ACTA AMAZONICA, Manaus, v. 46, p. 291-302, 2016.

BECKER, B. K. Geopolítica da Amazônia. Estudos Avançados, São Paulo, v. 19, n.53, p. 71-86, 2005.

CARD, D. H. Using known map category marginal frequencies to improve estimates of thematic map accuracy. Photogrammetric Engineering and Remote Sensing, USA, v. 48(3), p. 431-439, 1982.

CONGALTON, R. G. A review of assessing the accuracy of classifications of remotely sensed data. Remote Sensing of Environment, USA, v. 49, n. 12, p. 1671-1678, 1991.

GEIST, H. J.; LAMBIN, E. F. What Drives Tropical Deforestation? a meta-analysis of proximate and underlying causes of deforestation based on subnational case study evidence. Louvain-la-Neuve, Bélgica, ISSN: 1138-7424, 116 p., 2001.

IBGE. Mapa Integrado dos Zoneamentos Ecológico-Econômicos dos Estados da Amazônia Legal. Disponível em: http://www.ibge.gov.br/home/geociencias/geografia/mapas_doc5.shtm, 2017. Acesso em: mar. 2018. 
INPE. Projeto PRODES - Projeto de Estimativa de Desflorestamento da Amazônia. Taxas anuais do Desmatamento - 1988 até 2016, 2016. Disponível em: http://www.obt.inpe.br/prodes/ prodes_1988_2016n.htm. Acesso em: 15 jan. 2018.

INPE. GeoDMA Features. Disponível em: http://wiki.dpi.inpe.br/doku.php?id=geodma:features, 2017. Acesso em: 01 fev. 2018.

JENSEN, J. R. Sensoriamento Remoto do Ambiente: uma perspectiva em Recursos Terrestres. Tradução EPIPHANIO, J. C. N. et al. Parênteses, São José dos Campos, SP, 598 p., 2009.

KORTING, T.S.; FONSECA, L. M. G.; CÂMARA, G. GeoDMA - Geographic Data Mining Analyst a framework for GIScience. Computers \& Geosciences, USA, v. 57, p. 133-145, 2013.

MAURANO, L. E.; ADAMI, M. Ferramentas Web-Gis para avaliar exatidão de mapeamento de uso e cobertura da terra no Cerrado brasileiro. In: SIMPÓSIO BRASILEIRO DE SENSORIAMENTO REMOTO, 18, 2017, Santos. Anais... São José dos Campos: INPE, 2017, p. 462-469.

MCGARIGAL, K.; MARKS, B. J. FRAGSTATS: Spatial pattern analysis program for quantifying landscape structure. United State Department of Agriculture, Pacific Northwest Research Station General Technical Report PNW- GTR-351, Washington, 132 p., 1995.

MCROBERTS, R.E. Satellite image-based maps: Scientific inference or pretty pictures? Remote Sensing of Environment, USA, v. 115, p. 715-724, 2011.

NEPSTAD, D. et al. Slowing Amazon deforestation through public policy and interventions in beef and soy supply chains. Science, New York, v. 344, p. 1118-1123, 2014.

PONTUS O. et al. Good practices for estimating area and assessing accuracy of land change. Remote Sensing of Environment, USA, v148, p.42-57, 2014.

QUEIROZ, G. R. et al. WTSS: um serviço web para extração de séries temporais de imagens de sensoriamento remoto. In: Simpósio Brasileiro de Sensoriamento Remoto, 17, João Pessoa. Anais. São José dos Campos: INPE, 2015. p. 7553-7560.

QUINLAN, J.R. C5.0: an informal tutorial. 2017. Disponível em:

https://www.rulequest.com/see5-unix.html. Acesso em: 26 fev. 2018.

RUDORFF, B. F. T. et al. The Soy Moratorium in the Amazon Biome Monitored by Remote Sensing Images. Remote Sensing, Basel, v. 3, p. 185-202, 2011.

SAITO, E. A. et al. Efeitos da mudança de escala em padrões de desmatamento na Amazônia. RBCRevista Brasileira de Cartografia (Online), Brasil, v. 63, p. 401-414, 2011.

SPRACKLEN D.V.; ARNOLD S.R.; TAYLOR C.M. Observations of increased tropical rainfall preceded by air passage over forests. Nature, London, v. 489, p. 282-285, 2012.

TARDIN, A. T.; SANTOS, A. P.; NOVO, E. M. L. M. Projeto SUDAM: uso dos dados do Landsat no estudo do impacto da implantação de projetos agropecuários da Amazônia. São José dos Campos, 18 p., 1978.

TARDIN, A. T. et al. Levantamento de áreas de desmatamento na Amazônia Legal através de imagens do Satelite Landsat. São José dos Campos, 62 p., 1979.

TERRAAMAZON. TerraAmazon. 2017: Disponível em: http://terraamazon.org/index.php/pt/sobre. Acesso em: 20 abr. 2018.

VALERIANO, D. M. et al. O monitoramento do desmatamento. In: George Martine. (Org.). População e Sustentabilidade na Era das Mudanças Ambientais Globais. ABEP, Belo Horizonte, p. 223-238, 2012.

VIEIRA, IMA C. G.; ARAÚJO, R.; TOLEDO, P. M. Dinâmicas produtivas, transformações no uso da terra e sustentabilidade na Amazônia. In: Nelson Silfert; Marcus Cardoso; Walsey Magalhães; Helena Lastres. (Org.). Um Olhar Territorial para o Desenvolvimento da Amazônia. Rio de Janeiro, v., p. 370-395, 2014. 